University of Nebraska - Lincoln

DigitalCommons@University of Nebraska - Lincoln

2006

\title{
Long-Term Population Monitoring: Lessons Learned From an Endangered Passerine in Hawai'i
}

Luanne Johnson

Antioch University of New England

Richard J. Camp

United States Geological Survey

Kevin W. Brinck

United States Geological Survey

Paul C. Banko

United States Geological Survey, paul_banko@usgs.gov

Follow this and additional works at: https://digitalcommons.unl.edu/usgsstaffpub

Johnson, Luanne; Camp, Richard J.; Brinck, Kevin W.; and Banko, Paul C., "Long-Term Population Monitoring: Lessons Learned From an Endangered Passerine in Hawai'i" (2006). USGS Staff -- Published Research. 635.

https://digitalcommons.unl.edu/usgsstaffpub/635

This Article is brought to you for free and open access by the US Geological Survey at DigitalCommons@University of Nebraska - Lincoln. It has been accepted for inclusion in USGS Staff -- Published Research by an authorized administrator of DigitalCommons@University of Nebraska - Lincoln. 


\title{
Long-Term Population Monitoring: Lessons Learned From an Endangered Passerine in Hawai'i $i$
}

LUANNE JOHNSON, ${ }^{\mathbf{1}}$ Pacific Cooperative Studies Unit (University of Hawai'i at Mānoa), United States Geological Survey, Pacific Island Ecosystems Research Center, Kilauea Field Station, Hawai'i National Park, HI 96718, USA

RICHARD J. CAMP, Pacific Cooperative Studies Unit (University of Hawai'i at Mānoa), and Hawai'i Cooperative Studies Unit (University of Hawai'i at Hilo), United States Geological Survey, Pacific Island Ecosystems Research Center, Kilauea Field Station, Hawai'i National Park, HI 96718, USA

KEVIN W. BRINCK, Pacific Cooperative Studies Unit (University of Hawai'i at Mānoa), and Hawai'i Cooperative Studies Unit (University of Hawai'i at Hilo), United States Geological Survey, Pacific Island Ecosystems Research Center, Kilauea Field Station, Hawai'i National Park, HI 96718, USA

PAUL C. BANKo, ${ }^{2}$ United States Geological Survey, Pacific Island Ecosystems Research Center, Kilauea Field Station, Hawai i National Park, HI 96718, USA

\begin{abstract}
Obtaining reliable population estimates is crucial to monitoring endangered species and developing recovery strategies. The palila (Loxioides bailleui) is an endangered seed-eating Hawaiian honeycreeper restricted to the subalpine forests of Mauna Kea, a volcano on the island of Hawai'i, USA. The species is vulnerable to extinction primarily because $>90 \%$ of the population is concentrated in $<30 \mathrm{~km}^{2}$ of habitat on the western slope of this high, dormant volcano. Annual surveys of the palila population have been conducted for ecological, legal, and other purposes since 1980. Because refinements to sampling protocols and analytical methods have evolved, we examined means of adapting the monitoring program to produce comparable estimates of abundance over the past 25-year period and into the future. We conducted variable circular plot surveys during the nonbreeding season (JanMar) and this used data to obtain estimates of effective detection radius and annual density with Distance 4.0, Release 2. For comparability over the time-series, we excluded from analysis the data from new transects. We partitioned the 25-year data set (1980-1996 and 1997-2004) into 2 separate analyses because, beginning in 1997, observers received more training to reduce their tendency to estimate distances to 5-m intervals. We used geographic strata in the analysis of recent surveys because changes in habitat may have invalidated the density-based strata used previously. By adding observer and year and observer and time of day as co-variables, we improved the model fit to the 2 data sets, respectively. Annual estimates were confounded by changes in sampling methodology and analytical procedures over time. However, the addition of new transects, increased training for observers, and use of exact distance estimates instead of rounding also improved model fit. Habitat characteristics and behavior of palila that potentially influenced detection probability, sampling, analysis, and interpretation were regeneration of trees in response to reduced numbers of introduced browsing mammals, seasonally variable rates of vocalization, non-territoriality, and resourcetracking along an elevation gradient. We believe our adaptive approach to analysis and interpretation of 25 years of annual variable circular plot data could help guide similar long-term monitoring efforts. (WILDLIFE SOCIETY BULLETIN 34(4):1055-1063; 2006)
\end{abstract}

\section{Key words}

Hawai'i, Loxioides bailleui, palila, population monitoring, sampling methods, survey, variable circular plot.

Long-term monitoring programs are used to track the status of populations of endangered species. These programs also may reveal characteristics of species life histories or habitats that would not be apparent without knowledge of population trends over time (e.g., Taylor and Gerrodette 1993, Bennetts et al. 1999). Many recovery plans propose population densities that must be achieved before a population may be considered for delisting. Thus, monitoring and annual population estimates are integral to endangered species recovery.

For example, the 1986 revision of the original 1978 recovery plan for the endangered palila (Loxioides bailleui) specified that the population should occur at a minimum density of $25 \mathrm{birds} / \mathrm{km}^{2}$ throughout the currently occupied range (in 1986) before it could be considered for reclassification to threatened status (United States Fish

1 Present address: Antioch University New England, Keene, NH 03431, USA

2 E-mail: paul_banko@usgs.gov and Wildlife Service [USFWS] 1986). The latest draft of the recovery plan does not specify population size or density guidelines, but it requires that at least 3 self-sustaining populations should exist (USFWS, unpublished document). Under either plan, population surveys must occur frequently, if not annually.

There also are legal and social incentives to closely monitor the palila population. To protect palila critical habitat from destructive browsing, the Ninth District Federal Court has twice (in 1979 and 1986) ordered the eradication of feral goats (Capra hircus) and sheep (Ovis aries) and introduced wild sheep (O. gmelini musimon) and hybrids (Palila $v$. Hawaii Department of Land and Natural Resources, $471 \mathrm{~F}$. Supp. 985 [D. Hawaii 1979]; Palila v. Hawaii Department of Land and Natural Resources, 649 F. Supp. 1070 [D. Hawaii 1986]). For over 150 years, palila habitat on the island of Hawaii, USA, has been severely degraded by introduced feral ungulates that nearly eliminated recruitment of māmane (Sophora chrysophylla [Fabaceae]), killed 
small trees, and cropped the lower branches of larger trees as high as they could reach (Warner 1960).

The state of Hawai'i began removing goats and sheep in 1981, a year after systematic censuses using the variable circular plot $(\mathrm{VCP})$ method were begun to track changes in the palila population (Scowcroft and Giffin 1983, Jacobi et al. 1996). The state is required to provide the court with annual estimates of the palila population on Mauna Kea as well as the numbers of ungulates removed. Although monitoring habitat recovery was not legally required, studies of vegetation structure and composition began in the late 1990s and after māmane regeneration was evident (United States Geological Survey [USGS], unpublished data). Some game hunters and other members of the public also follow palila population trends, wishing to know whether numbers are increasing as the habitat recovers from long-term ungulate browsing. For these and other reasons, it is important that annual surveys be carefully conducted and interpreted.

Designing a long-term monitoring program for palila must account for its ecology in several ways. Foremost is its high degree of specialization on the seeds of māmane, an endemic dry-forest tree. Palila are restricted, therefore, to habitats where māmane is common, and during the past 50 years, the population has become restricted to a high-elevation remnant of māmane woodland on Mauna Kea, a high, dormant volcano (Banko et al. 2002a). Māmane flowers and sets seed first at high elevation and months later at low elevation, and individual seeds are suitable as food over approximately 4 months (van Riper et al. 1978, van Riper 1980a, Banko et al. 2002b). Thus, contiguous habitat distributed along a substantial elevational gradient provides palila with optimal foraging opportunities throughout most of the year (Scott et al. 1984, Banko et al. 2002b). Palila loosely track the seasonal availability of māmane seeds over short distances $(<6 \mathrm{~km})$ up and down the slopes of Mauna Kea, but they are nonmigratory, non-territorial, and do not wander far around the flanks of the volcano in search of food or mates (Fancy et al. 1993, Hess et al. 2001). Temporary and diffuse concentrations of birds are most noticeable before the peak of nesting and after the nesting season. Annual and seasonal availability of māmane seeds varies substantially, affecting palila survival as well as the timing and duration of nesting and the number of nests attempted (Lindsey et al. 1995, 1997, Pratt et al. 1997). The palila population occurs above the range of introduced mosquitoes, which transmit avian malaria and pox to other Hawaiian birds at lower elevations (Warner 1968, van Riper et al. 1986), but feral cats and other alien predators pose significant threats to nesting birds, although there is no indication that annual predation rates vary greatly (Banko et al. 2002a,b).

During the course of a long-term monitoring program, habitat and environmental conditions may change, personnel and resources necessary to carry out surveys may vary from year to year, or new technologies and procedures may emerge that affect data collection, analysis, and interpretation. Objectives of monitoring programs also may change as habitat and other environmental conditions change or as knowledge of the ecology of the species improves. For example, surveillance monitoring of an endangered species may eventually include populations of other species, habitat response variables, or environmental variables that are influenced by management. The palila monitoring program has experienced all of these changes.

Initial surveys were undertaken in 1975 to determine population size, density, and distribution of the palila in relation to vegetation structure and phenology (van Riper et al. 1978). Surveys that followed during 1980-1985 examined annual variation in abundance and distribution and the response of the population to habitat variables to infer factors that were limiting the population and to develop management strategies (Scott et al. 1984). These surveys also employed the VCP method for estimating population densities and established the basic temporal and spatial framework for monitoring that continues today. Population estimates obtained after 1984 were not linked to habitat variables, and sampling and analytical methods changed in a variety of ways (Jacobi et al. 1996, Banko et al. 1998, Gray et al. 1999).

In this paper we present the rationale and methods by which we adjusted the monitoring program to produce comparable estimates of abundance over a 25 -year period as objectives and technical and logistical capabilities changed. We report the results of annual surveys from 1999 to 2004 and reanalyze original data from 1980 to 1998 to track longterm population changes. Because analytical methods have changed since palila population estimates were last published (Gray et al. 1999), we endeavored to standardize estimates while limiting the influence of methodological and analytical changes over time. Observer calibration and training in distance estimation became more rigorous beginning in 1997, when new transects were also added, and advances in software and computer technology provided more accurate analytical estimation techniques. Recognizing that habitat conditions were changing as populations of feral ungulates were being reduced, detailed studies of vegetation structure and composition and food availability were undertaken in the late 1990s (USGS, unpublished data), and these results will soon be used to test hypotheses about relationships of this specialist seed-eater to its environment.

\section{Study Area}

We conducted annual surveys around the upper slopes of Mauna Kea $\left(19^{\circ} 50^{\prime} \mathrm{N}, 155^{\circ} 35^{\prime} \mathrm{W}\right)$, which is the highest peak $(4,205 \mathrm{~m})$ and second largest volcano in the archipelago (Fig. 1). Survey transects extended from the lower to upper subalpine zone (approx. 2,000- to 3,000-m elevation), which lay above the trade-wind inversion, the layer resulting from the meeting of air descending from the upper atmosphere and air rising off the earth's surface (Juvik and Juvik 1998). The trade-wind inversion acted as a ceiling to rising, moist air, which resulted in relatively light cloud cover and rainfall in the subalpine and alpine zones. Rainfall averaged $511 \mathrm{~mm}$ annually in subalpine Mauna Kea, but up to $38 \%$ more precipitation dripped from trees that intercepted ground 
clouds brought by the frequent daytime upslope winds (Juvik and Nullet 1993, Juvik et al. 1993). The wettest months were January through April and August, with average monthly rainfall exceeding $50 \mathrm{~mm}$; June tended to be the driest month, with rainfall averaging $<20 \mathrm{~mm}$ (J. O. Juvik, University of Hawai' $i$ at Hilo, unpublished data). Temperature averaged $11.1 \pm 1.5^{\circ} \mathrm{C}$ annually. Substrates were primarily thoroughly drained volcanic cinder and ash that ranged in age from 4,000 to $>14,000$ years and lava flows that ranged in age from 4,400 to $>65,000$ years (Wolfe and Morris 1996). Much of the organic soil layer had been lost to erosion due to severe overgrazing from introduced feral cattle, sheep, and goats (Warner 1960). Periodic reductions of populations of feral browsers in the past 25 years had allowed māmane and many other native plants to regenerate, and recent changes in the structure and composition of the woodland vegetation of the subalpine zone have been described by Hess et al. (1999). Overall, tree canopy was open but converging as young trees slowly filled in gaps. Māmane was the dominant tree around Mauna Kea, but another native tree, naio (Myoporum sandwicense), codominated on the western and southern slopes. Native shrubs were common in many areas. Alien grasses tended to dominate at low and mid-elevations, whereas native species were more common at higher elevations.

\section{Methods}

In all annual surveys of palila during the nonbreeding season (Jan-Mar), beginning in 1980, observers used the VCP method (Reynolds et al. 1980; also called point transect distance sampling) with 6-minute counts. Counts were conducted every $150 \mathrm{~m}$ at permanent stations along 17 randomly placed transects, except in 1996 when only 6 transects were surveyed (Scott et al. 1984, Jacobi et al. 1996, Banko et al. 1998, Gray et al. 1999).

An additional 14 transects were established between 1997 and 1998, including some placed to survey core palila habitat more intensively to produce a more precise population estimate and others to provide more complete coverage of the range of the palila and other bird species occupying subalpine habitat (Fig. 1); however, we analyzed only data collected on the original 17 transects in this paper. This procedure standardized our data set and eliminated bias introduced by the new, non-randomly established transects.

Observers were trained as suggested by Kepler and Scott (1981) for all counts; however, beginning in 1997, our training emphasized the importance of reporting consistent and accurate exact distance estimates. We also trained observers to identify all species of passerine species (not just palila and a few other species of interest as was done during

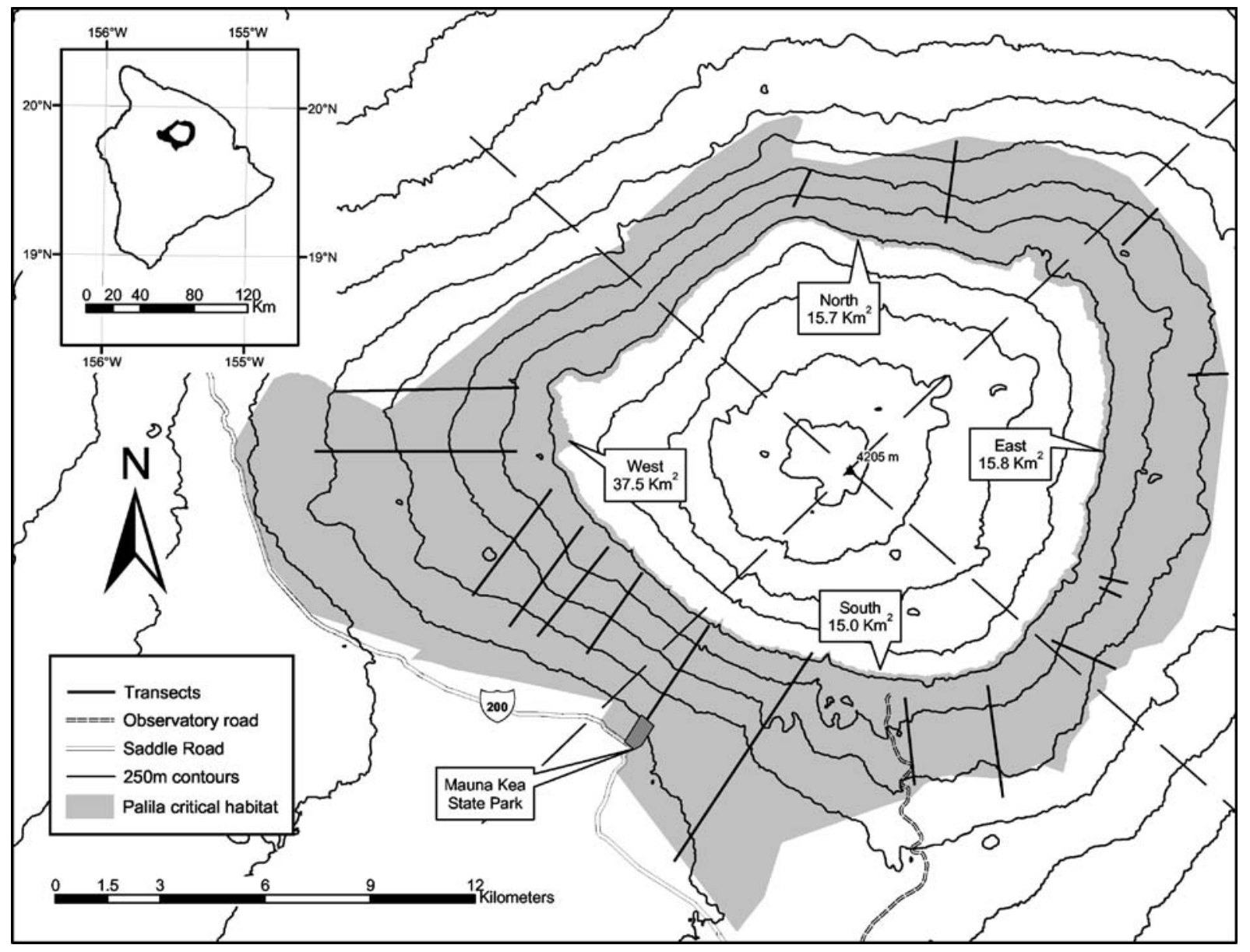

Figure 1. Transects across Mauna Kea, Hawai'i, USA, used for annual censuses (1980-2004) of the palila population. Transects were allocated to 4 geographic strata. The area of each stratum is shown in square kilometers. 
the 1985-1996 period). Because palila usually are detected aurally ( $>90 \%$ of detections; 1,686 of 1,806 in the 1980 1996 data set and 930 of 954 in the 1997-2004 data set), we gave special attention to estimating distances to calling or singing birds and to the importance of trying not to influence the behavior or movement of birds while approaching the census station or during the count (orange vests were required be worn at all times for safety from hunters, but palila and other species seem relatively unresponsive to bright clothing). Observers recorded distance estimates and detection type (aural, ocular, or both) on counts that occurred between 0545 and 1300 hours. They reported cloud cover in $10 \%$ increments and used the Beaufort scale to record wind speed and gusts. Observers recorded precipitation on a scale of 0 (no precipitation) to 4 (heavy rain), and counts ceased when wind speed exceeded $30 \mathrm{~km} / \mathrm{hour}$, or during heavy rain (Scott et al. 1984, Jacobi et al. 1996, Banko et al. 1998, Gray et al. 1999). Twice during each annual survey between 1980 and 1990, observers (usually an experienced person and a trainee) sampled approximately 60 stations on 3 transects passing through the most densely occupied (core) portion of the habitat. For our analysis of these replicates, we used data from the most experienced observer as long as wind was $<3$ on the Beaufort scale. If wind speed was $\geq 3$ on the Beaufort scale, we used data collected during the best wind conditions.

For analysis, we divided the 25-year data set into 2 pooled groups: 1980-1996 and 1997-2004, based on differences in observer training. We examined histogram detection distances for the 2 groups (Fig. 2A,B) and concluded that distance estimation differed after observers were trained to estimate distances at $1-\mathrm{m}$ intervals and to avoid rounding to 5-m intervals. Such rounding was evident in the 1980-1996 data. We pooled observations within these groups to increase sample size (see Ramsey et al. 1987, Fancy 1997).

We used Distance 4.0, Release 2 (Thomas et al. 2002) to determine the best-fit model and calculated an effective detection radius (EDR) and its percent coefficient of variation $(\mathrm{CV})$ for each data set. We binned the 19801996 data due to rounding to 5-m intervals, and we analyzed the 1997-2004 data as exact distances. Data sets were truncated at the distance where $g(r)=0.10$ or with best fit to the data (Buckland et al. 1993, Thomas et al. 2002).

We accounted for differences in sampling conditions by using the covariate analysis in the Multiple Covariates Distance Sampling Module (MCDS) of Distance 4.0. This module allowed the probability of detection of a bird to change with covariates, as well as radial distance. We tested for model improvement with the following co-variables: time of day (pooled into half-hour periods), cloud cover, sustained wind, maximum wind gust, rain, observer, and year. We pooled observers with $<25$ detections. We treated year, observer, wind, gust, and rain as categorical variables. We treated time of day and cloud cover as continuous variables in MCDS. We selected the best-fit model using recommendations provided by Buckland et al. (1993, 2001), Burnham and Anderson (2002), and the Distance 4.0 user's guide (Thomas et al. 2002).
We used geographic strata dividing the mountain by quadrants in cardinal directions rather than the densitybased strata created for analysis in the early 1980s (Scott et al. 1984) and overlain upon the preexisting transects. We originally placed the survey transects around the entire mountain without regard to stratification and later superimposed the density-based strata upon the existing sampling framework. Forest structure changed since ungulate removal began in 1981 (Hess et al. 1999), and palila have undoubtedly responded to changes in habitat throughout its range. We believe these habitat changes have invalidated the density-based strata used in prior analyses (Scott et al. 1984, Jacobi et al. 1996, Banko et al. 1998, Gray et al. 1999) and so have used deliberate geographic divisions that reduce within-strata variation versus the habitat as a whole.

Using the EDR provided by Distance 4.0, we produced density and mean population estimates for each of the 4 geographic strata (north, south, east, west; Fig. 1). To account for variability of palila density within each geographic stratum, we calculated confidence intervals for

A)

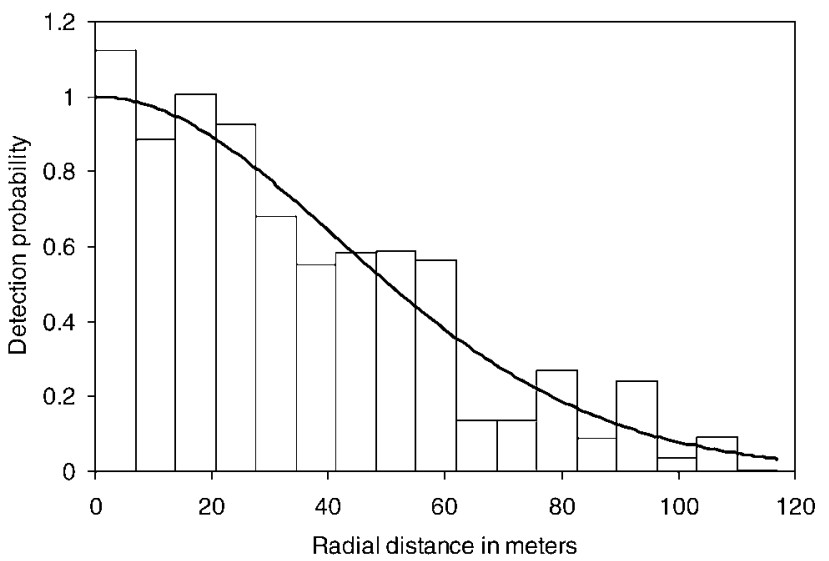

B)



Figure 2. Detection probability plots from Program Distance analysis on palila population size estimates in Mauna Kea, Hawai'i, USA. (A) Data from 1980 to 1996 grouped into 17 equal interval groups and truncated at $116 \mathrm{~m}$. (B) Data from 1997 to 2004 where distance measurements were exact, truncated at $80 \mathrm{~m}$. 
the population estimates from 5,000 bootstrap samples of point transects within strata. We used a generalized additive model (GAM) to detect long-term trends and define major features of population trends (Fewster et al. 2000). The GAM was fitted to a second-degree loess smoother with a span of 0.5 and an approximate, nonparametric 17.9 residual degrees of freedom. We estimated approximate 95\% confidence intervals from bootstrap techniques.

\section{Results}

We obtained a best fit to the 1980-1996 data using a halfnormal key model with right-truncation at $116 \mathrm{~m}$ and binning into 17 groups, with approximately the same number of observations in each group while ensuring that favored distances did not fall on cutpoints (see Buckland et al. 2001: $155,160-161)$. This produced an EDR of $62.4 \mathrm{~m}$ with a CV of $1.14 \%$ using 1,629 palila detections (Fig. 2A). Adding observer as a co-variable improved the model fit to the data, but no other co-variables were selected for the final model.

We obtained a best fit to the 1997-2004 data using a hazard rate key model with right-truncation at $80 \mathrm{~m}$. This produced an EDR of 59.9 m with a CV of $1.7 \%$ using 1,021 palila detections (Fig. 2B). Adding year, observer, and time of day as co-variables improved the model fit to the data. The entire series of population estimates (Fig. 3) revealed a population decline in the mid-1980s followed by an uneven return to higher levels in the late 1990s and early 2000s.

In all survey years, at least $90 \%$ of the palila population estimate was in the western stratum, between transects 101 and 105 on the southwestern slope of Mauna Kea between $1,841 \mathrm{~m}$ and 2,909 $\mathrm{m}$ elevation (Fig. 1). The annual mean population estimate during 1980-2004 ranged from a low of 767 birds in 1992 to a high of 3,367 in 1998 (Table 1, Fig. 3 ), a $43 \%$ average change in population size estimates. The 25-year mean was 2,114 palila, with a standard error of 154 .

\section{Discussion}

Few other endangered bird species have been monitored as long as palila. Whooping cranes (Grus americana) have been monitored since 1938 (Boyce 1987), Kirtland's warbler (Dendroica kirtlandii) since 1951 (Mayfield 1992), and the Florida snail kite (Rostrhamus sociabilis) since 1969 (Bennetts et al. 1999). The whooping crane has exhibited a decadal cycle of survivorship associated with wet-dry cycles in the nesting area (Boyce and Miller 1985, Lewis 1995), a pattern that would not have been detected without longterm monitoring. The Kirtland's warbler has demonstrated positive population response to large-scale fires (Mayfield 1992), a response that could not have been detected without a history of prefire measurements, and snail kite abundance may be affected by changes in water levels (Bennetts et al. 1999). Like the latter 2 species, palila abundance, or at least their detectability, also varies strongly and likely is driven by interannual climate differences as they affect their environment and food resources.

We estimated the 25-year average palila population size to be slightly more than 2,000 birds. Palila were concentrated in the western stratum of Mauna Kea ( $>90 \%$ of the palila population). This was not surprising as the māmane forest on the southwestern slope provides the largest elevation gradient of any remaining habitat on the volcano (Scott et al. 1984, Jacobi et al. 1996, Banko et al. 1998, Gray et al. 1999). Previously published studies indicate that palila densities fluctuate annually (Scott et al. 1984, Jacobi et al. 1996, Banko et al. 1998, and Gray et al. 1999). Similar to previous studies, our annual population estimates fluctuated widely with more than a 5 -fold difference between the smallest and largest annual population size estimates. Longterm population monitoring can provide valuable insights into population variability and factors that drive population

\section{Annual palila population estimates 1980-2004}

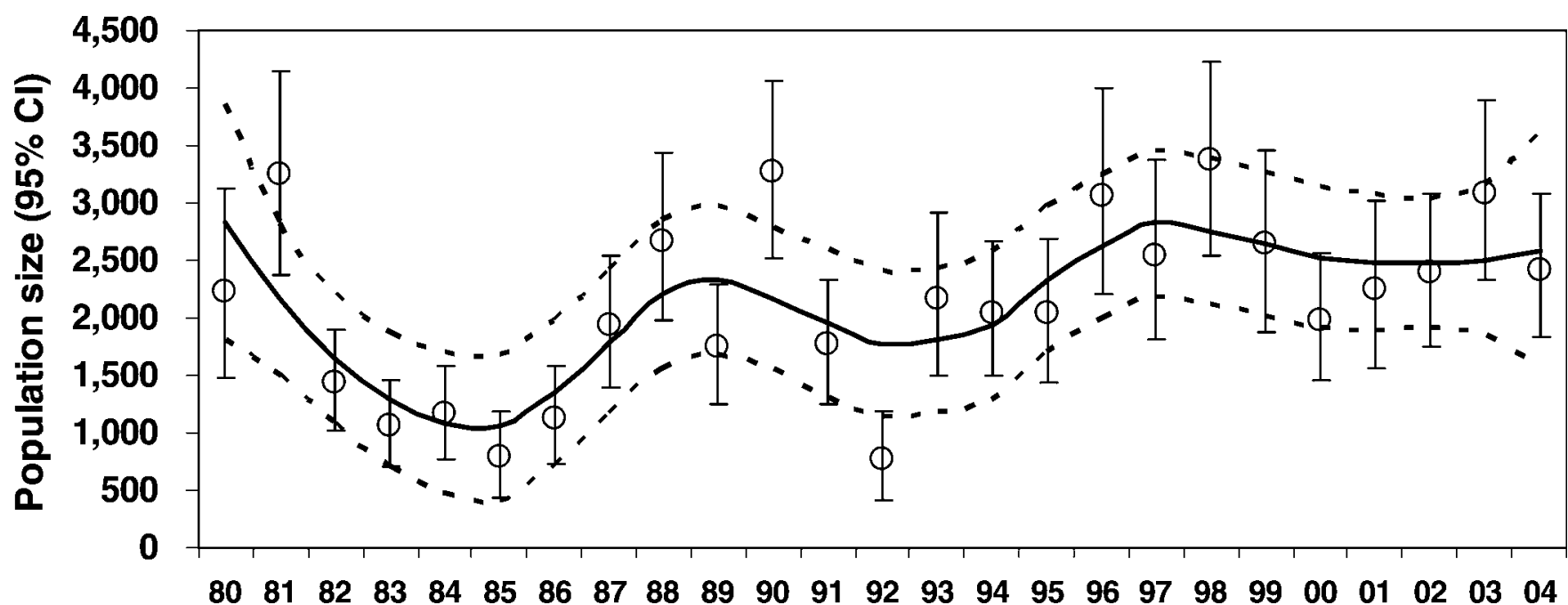

Figure 3. Palila population estimates by year (1980-2004) with 95\% confidence intervals, obtained along slopes of Mauna Kea, Hawai'i, USA. The smooth trend line was obtained by fitting a generalized additive model to the population estimates. The dashed lines represent an approximate $95 \%$ confidence envelope around that curve. 
Table 1. Mean population (pop.) estimate, standard error of the mean (SE), and 95\% confidence interval (Cl) by year of palila abundance on Mauna Kea, Hawai'i, USA, estimated using Distance 4.0, Release 2, with data from variable circular point surveys. The original published annual population estimates (Scott et al. 1984, Jacobi et al. 1996, Banko et al. 1998, Gray et al. 1999) are included with the percent change. In 1996 only 6 transects were surveyed: 5 transects in the west quadrant and 1 transect in the east quadrant.

\begin{tabular}{lccccc}
\hline Year & Mean pop. size & SE & \multicolumn{1}{c}{$\mathbf{9 5 \%} \mathbf{C l}$} & Original published mean pop. size & Change in pop. estimate \\
\hline 1980 & 2,238 & 415 & $1,483-3,118$ & 4,592 & $-51 \%$ \\
1981 & 3,240 & 447 & $2,374-4,145$ & 5,685 & $-43 \%$ \\
1982 & 1,438 & 219 & $1,026-1,887$ & 4,224 & $-66 \%$ \\
1983 & 1,063 & 188 & $715-1,449$ & 2,177 & $-51 \%$ \\
1984 & 1,160 & 209 & $778-1,577$ & 2,903 & $-60 \%$ \\
1985 & 786 & 193 & $442-1,189$ & 1,584 & $-50 \%$ \\
1986 & 1,120 & 215 & $721-1,576$ & 5,778 & $-37 \%$ \\
1987 & 1,940 & 291 & $1,398-2,536$ & 4,405 & $-63 \%$ \\
1988 & 2,672 & 380 & $1,969-3,437$ & 3,859 & $-39 \%$ \\
1989 & 1,745 & 265 & $1,249-2,283$ & 4,498 & $-55 \%$ \\
1990 & 3,275 & 398 & $2,525-4,062$ & 2,724 & $-27 \%$ \\
1991 & 1,768 & 276 & $1,242-2,330$ & 1,753 & $-35 \%$ \\
1992 & 767 & 194 & $427-1,178$ & 4,130 & $-56 \%$ \\
1993 & 2,163 & 355 & $1,505-2,914$ & 2,691 & $-48 \%$ \\
1994 & 2,046 & 299 & $1,501-2,662$ & 2,056 & $-24 \%$ \\
1995 & 2,036 & 317 & $1,442-2,696$ & 4,117 & $-1 \%$ \\
1996 & 3,060 & 455 & $2,210-4,007$ & 4,396 & $-26 \%$ \\
1997 & 2,551 & 404 & $1,806-3,381$ & 5,436 & $-42 \%$ \\
1998 & 3,367 & 426 & $2,552-4,219$ & & $-38 \%$ \\
1999 & 2,645 & 403 & $1,874-3,451$ & & \\
2000 & 1,985 & 287 & $1,454-2,566$ & & \\
2001 & 2,252 & 379 & $1,553-3,029$ & & \\
2002 & 2,392 & 338 & $1,756-3,079$ & & \\
2003 & 3,090 & 393 & $2,338-3,893$ & & \\
2004 & 2,419 & 313 & $1,841-3,074$ & & \\
\hline
\end{tabular}

change, such as environmental conditions and climate. Over the course of the palila monitoring program, most facets of the field sampling protocol have remained the same. In all years 6-minute point counts were conducted approximately at the same time of year (Jan-Mar) on the same 17 transects, and the same co-variables were measured. The 1996 survey was the only exception, with only 6 transects surveyed in early March, shortly before many pairs began nesting. Beginning in 1997, we gave observers more extensive training in distance estimation and they began reporting exact distances rather than binned distances. Therefore, our current analysis fit a different model for each time period (1980-1996 and 1997-2004).

A half-normal model best fit the 1980-1996 data, while a hazard rate model best fit the 1997-2004 data. We analyzed data in each time period separately because observer training and distance recording methods differed and because 19801996 data were rounded to even distances. It also is possible that changes in forest structure over time influenced detection probability; for instance, a cohort of small trees now populates areas near transect stations that once were devoid of young māmane trees. The general form of the detection function decreases with increasing distance (Buckland et al. 2001). Data that decline rapidly with distance typically are fitted with the half-normal function, and this function represented the 1980-1996 data. In contrast, data that possess a shoulder for some distance from the point, like the 1997-2004 data, are best fit with the hazard rate model.

More than 70 different observers participated in palila surveys between 1980 and 2004; thus, it is not surprising that adding observer as a co-variable improved the model fit in both the 1980-1996 and the 1997-2004 pooled data sets. No other co-variable improved the fit of the 1980-1996 data, but year and time of day were important co-variables in the 1997-2004 data analysis.

Because palila are nonmigratory and the entire population was resident within the area surveyed, all birds were available for detection. Year as a co-variable included several types of annual variation that may have influenced palila detectability during each survey. The number of palila vocalizing during the annual survey window largely influenced population estimates because $>90 \%$ of palila were detected by their vocalizations. Although we did not investigate factors influencing daily and seasonal vocalization rates, our experience in the field suggests that palila vocalization rates likely were linked to gender, age class, and proximity of the breeding season to the annual survey.

Palila are non-territorial and, thus, do not sing at fixed sites throughout the breeding season. However, they do sing and call frequently during courtship (van Riper 1980b). Moreover, van Riper et al. (1978) found that palila were more detectable before the nesting season (Jan) than after the nesting season (Sep). The palila breeding season can begin anytime from February to June in response to food resources and weather as the number of pods and flowers available in a given year fluctuates with weather patterns. While the average productivity of pairs remained fairly constant, the number of nests initiated and the length of the breeding 
season influenced the number of juveniles added to the population each year (Pratt et al. 1997, Banko et al. 2002a).

The 1980-2004 counts were conducted between January and March, before the usual peak of nesting during MayJuly (Banko et al. 2002a). However, in some years, surveys would have been conducted just at the beginning of nesting, whereas in other years surveys would have preceded nesting by at least several months. For example, January count data for 1993 and 1996, just before the breeding season in those years, produced population estimates showing substantial increases from 1992 and 1995. However, these estimates were biologically counterintuitive because 1992 and 1995 were drought years, when few birds nested and few birds were detected in annual counts. Furthermore, low numbers of birds were captured in mist-nets during 1992 (Lindsey et al. 1997). Yet, many pairs nested over several months in 1993 and 1996 (Pratt et al. 1997). We believe that palila may be less vocal and more dispersed throughout the habitat when resources are limited, which reduces their detectability. Thus, it is likely that some of the annual variation in population estimates is due to variation in detectability rather than true population decreases and increases. Food availability also might have affected detection rates, if not vocalization rates. A study of these and other factors on seasonal vocalization rates is needed to guide interpretation of annual survey data and perhaps timing of annual surveys.

El Niño-Southern Oscillation climate cycles have occurred throughout the study period, with notable droughts in 1983, 1987, 1992, 1995, and 1998. Other environmental perturbations, such as large wildfires, have not occurred within the core area of habitat for many decades. Feral sheep and other ungulates have disturbed palila habitat most in the long term. Since ungulate removal began in 1981, the density of mature trees has increased and the lower branches of individual trees have grown back, resulting in greater food availability to palila (Hess et al. 1999). In our current analysis, the geographically based stratification avoided stratification criteria based on the condition of the māmane forest that might change over time. Differences between our population size estimates and previously published estimates may be due to different stratification procedures. As the māmane expands outside of the original dense stratum, the birds would follow, increasing the count in the original, larger, low-density stratum and producing an overestimate of abundance.

Scott et al. (1984) stratified by dividing habitat on Mauna Kea by elevation into high, low, and historical density levels based on previous surveys. They then used VCP analysis methods as described in Ramsey and Scott (1981) with correction factors for observer and vegetation type. Scott et al. (1986) corrected their observations for forest type, canopy, and elevation.

Jacobi et al. (1996) stratified sampling stations based on total number of detections in previous years, with boundaries delineated by elevation and vegetation type. Their analyses used the method described by Fancy (1997), in which detection distances were calibrated to a set of reference conditions (a standard observer, time, cloud cover, wind, gust, and rain). This calibration was used to adjust the recorded detection distance according the specific conditions of the observation, and the adjusted distances were then analyzed using standard VCP techniques.

In Gray et al. (1999), palila habitat was stratified similarly to Jacobi et al. (1996). The same analytical technique was used, but additional transects were added. Some of these new transects were nonrandomly assigned to the highestdensity palila habitat on the western slope of Mauna Kea in order to increase precision of the abundance estimate at the expense of adding an upward bias to the final abundance estimate. Other transects were added to increase overall coverage within the palila's range and to increase the probability of detecting palila in areas where māmane regeneration was improving. Throughout palila monitoring, the best available analytical techniques were used. The theory underlying distance estimation techniques has remained the same, and the process of choosing a truncation distance and constructing a model has been consistent, if not constant, for each analysis. However, the exact details of the statistical methods have changed with advances in theory and computation technology. In our current analysis, we used information-theoretic criteria for choosing models and maximum likelihood methods to analyze effects of covariates rather than previous methods of goodness-of-fit tests and modification of raw data (Scott et al. 1984, 1986, Jacobi et al. 1996, Banko et al. 1998, Gray et al. 1999).

We expect that field procedures, environmental conditions, and analytical techniques will continue to change and that the forest will continue to regenerate. Equipping all field observers with laser rangefinders will further improve accuracy of observed distances, and use of stratification techniques that encompass changes in regenerating forest will improve the accuracy of density estimates. Computer technology will continue to improve, at the very least allowing consideration of increasingly complex models. By continuing to evaluate the monitoring program and analyze the data to produce comparable estimates, we will be able to address these potential difficulties. Accurate and consistent monitoring of the palila population requires that we improve the calibration of aural detections and more closely integrate data collection and analysis to identify violations of the model assumptions. Including vegetation data from stations on each transect as a co-variable and perhaps augmenting VCP counts with other methods of abundance estimation, such as monthly indices of palila vocalizations or capturerecapture frequency, should help guide management of this endangered species and its habitat.

\section{Management Implications}

Ideally, the objectives of a long-term population-monitoring program are set at the beginning of the project (Cochran 1977) but, over the course of the program, changes in environmental conditions, field protocols, or analytical techniques may yield abundance estimates that are not comparable to those obtained earlier. To ensure that the 
original objectives of monitoring can still be met, comparable estimates must be produced as circumstances change. Sometimes, such consistency requires ignoring information that would allow more precise estimates in later years. In our case we ignored data collected in later years on the nonrandom transects.

The initial sampling methodology should be retained even in the face of new, better methods until they can be calibrated or converted. The best analytical technique available should be used whenever possible. This suggests that the design of long-term monitoring programs should attempt at the outset to collect data that is robust to analysis by a variety of techniques. Sometimes this may require collecting information that has no immediate use when first collected. However, planning a long-term monitoring program often is not an option because of uncertain budgets and other vagaries inherent in conservation activities. Instead, repeated surveys may accumulate until they become de facto long-term monitoring. This situation will limit the analysis and interpretation of results and likely will require compromises in planning future surveys. It may be difficult to decide, for example, whether to continue the basic survey methods to identify population trends over a long time or to initiate new methods that may not allow for comparisons with earlier results but that are needed to meet new monitoring objectives. To mitigate for this, we suggest that initial surveys be planned with care and with the possibility of accommodating long-term monitoring.

Long-term monitoring should guide adaptive management schemes that also incorporate research on the natural history and behavioral ecology of the species. Periodic data on reproduction, survival, and food resources will inform

\section{Literature Cited}

Banko, P. C., S. C. Hess, L. Johnson, and S. J. Dougill. 1998. Palila population estimate for 1997. 'Elepaio 58:11-15.

Banko, P. C., L. Johnson, G. D. Lindsey, S. G. Fancy, T. K. Pratt, J. D. Jacobi, and W. E. Banko. 2002a. Palila (Loxioides bailleui). Number 679 in A. Poole and F. Gill, editors. The birds of North America. The Academy of Natural Sciences, Philadelphia, Pennsylvania, and American Ornithologists' Union, Washington, D.C., USA.

Banko, P. C., P. T. Oboyski, J. W. Slotterback, S. J. Dougill, D. M. Goltz, L. Johnson, M. E. Laut, and C. Murray. 2002b. Availability of food resources, distribution of invasive species, and conservation of a Hawaiian bird along a gradient of elevation. Journal of Biogeography 29:789-808.

Bennetts, R. E., W. A. Link, J. R. Sauer, and P. W. Sykes Jr. 1999. Factors influencing counts in annual surveys of snail kites in Florida. Auk 116:316-323.

Boyce, M. S. 1987. Time-series analysis and forecasting of the Aransas-Wood Buffalo whooping crane population. Pages 1-9 in J. C. Lewis and J. W. Ziewitz, editors. Proceedings of the 1985 International Crane Workshop. Platte River Whooping Crane Habitat Maintenance Trust and United States Fish and Wildlife Service, 2628 March 1985, Grand Island, Nebraska, USA.

Boyce, M. S., and R. S. Miller. 1985. Ten-year periodicity in whooping crane census. Auk 102:658-660.

Buckland, S. T., D. R. Anderson, K. P. Burnham, and J. L. Laake. 1993. Distance sampling: estimating abundance of biological populations. Chapman and Hall, London. 1999 reprint. Research Unit for Wildlife Population Assessment, University of St. Andrews, St. Andrews, United Kingdom.

Buckland, S. T., D. R. Anderson, K. P. Burnham, J. L. Laake, D. L. adaptive project design, data interpretation, and analysis of population trends. This new biological information will allow improved sampling designs and more accurate abundance estimates. When the progress of long-term projects is evaluated, field protocols or analysis techniques should be altered to accommodate changes in field conditions or advances in technique or technology. The palila monitoring program exceeds that for most other bird species, and similarly long time series are needed to understand population trends of many more endangered species. We encourage others to consider monitoring programs for other species based upon the model we describe here for palila.

\section{Acknowledgments}

This research was made possible thanks to support from United States Army Garrison, Hawai i; Federal Highway Administration; and United States Geological Survey Wildlife and Terrestrial Resources Program. Hawaici Division of Forestry and Wildlife granted permission to work in the Mauna Kea State Forest Reserve, and we thank their staff for participating in annual surveys. We are grateful to the many people who helped conduct surveys or otherwise facilitated our work, especially C. Murray, S. Hess, C. Farmer, E. Gray, and M. Laut. We thank S. Schweitzer for her careful review and editorial assistance, and we thank 2 anonymous reviewers for their helpful comments. Any use of trade, product, or firm names in this publication is for descriptive purposes only and does not imply endorsement or censure by the United States Government.

Borchers, and L. Thomas. 2001. Introduction to distance sampling: estimating abundance of biological populations. Oxford University, Oxford, United Kingdom.

Burnham, K. P., and D. R. Anderson. 2002. Model selection and multimodel inference: a practical information-theoretic approach. Second edition. Springer, New York, New York, USA.

Cochran, W. G. 1977. Sampling techniques. Third edition. Wiley \& Sons, New York, New York, USA.

Fancy, S. G. 1997. A new approach for analyzing bird densities from variable circular-plot counts. Pacific Science 51:107-114.

Fancy, S. G., R. T. Sugihara, J. J. Jeffrey, and J. D. Jacobi. 1993. Site tenacity of the endangered palila. Wilson Bulletin 105:587-596.

Fewster, R. M., S. T. Buckland, G. M. Siriwardena, S. R. Baillie, and J. D. Wilson. 2000. Analysis of population trends for farmland birds using generalized additive models. Ecology 81:1970-1984.

Gray, E. M., P. C. Banko, S. J. Dougill, D. Goltz, L. M. Johnson, M. E. Laut, J. D. Semones, and M. R. Wiley. 1999. Breeding and nonbreeding censuses of the 1998 palila population on Mauna Kea, Hawai'i. 'Elepaio 59:33-39.

Hess, S. C., P. C. Banko, G. J. Brenner, and J. D. Jacobi. 1999. Factors related to the recovery of subalpine woodland on Mauna Kea, Hawaii. Biotropica 31:212-219.

Hess, S. C., P. C. Banko, M. H. Reynolds, G. J. Brenner, L. P. Laniawe, and J. D. Jacobi. 2001. Drepanidine movements in relation to food availability in subalpine woodland on Mauna Kea, Hawai'i. Studies in Avian Biology 22:154-163.

Jacobi, J. D., S. G. Fancy, J. G. Giffin, and J. M. Scott. 1996. Longterm population variability in the palila, an endangered species. Pacific Science 50:363-370. 
Juvik, J. O., and D. Nullet. 1993. Relationships between rainfall, cloudwater interception, and canopy throughfall in a Hawaiian montane forest. Pages 102-113 in Tropical Montane Cloud Forests, Proceedings of an International Symposium, 31 May-5 June 1993, San Juan, Puerto Rico, USA. Produced by East-West Center, Program on the Environment, Honolulu, Hawai'i, USA.

Juvik, J. O., D. Nullet, P. C. Banko, and K. Hughes. 1993. Forest climatology near the tree line in Hawai $i$. Agricultural and Forest Meteorology 66:159-172.

Juvik, S. P., and J. O. Juvik. 1998. Atlas of Hawai'i. Third edition. University of Hawai' i, Honolulu, USA.

Kepler, C. B., and J. M. Scott. 1981. Reducing bird count variability by training observers. Studies in Avian Biology 6:366-371.

Lewis, J. C. 1995. Whooping crane (Grus americana). Number 153 in A. Poole and F. Gill, editors. The birds of North America. The Academy of Natural Sciences, Philadelphia, Pennsylvania, and American Ornithologists' Union, Washington, D.C., USA.

Lindsey, G. D., S. G. Fancy, M. H. Reynolds, T. K. Pratt, K. A. Wilson, P. C. Banko, and J. D. Jacobi. 1995. Population structure and survival of palila. Condor 97:528-535.

Lindsey, G. D., T. K. Pratt, M. H. Reynolds, and J. D. Jacobi. 1997. Response of six species of Hawaiian forest birds to a 1991-1992 El Niño drought. Wilson Bulletin 109:339-343.

Mayfield, H. F. 1992. Kirtland's warbler (Dendroica kirtlandii). Number 19 in A. Poole, P. Stettenheim, and F. Gill, editors. The birds of North America. The Academy of Natural Sciences, Philadelphia, Pennsylvania, and the American Ornithologists' Union, Washington, D.C., USA.

Pratt, T. K., P. C. Banko, S. G. Fancy, G. D. Lindsey, and J. D. Jacobi. 1997. Status and management of the palila, an endangered Hawaiian honeycreeper, 1987-1996. Pacific Conservation Biology 3:330-340.

Ramsey, F. L., and J. M. Scott. 1981. Analysis of bird survey data using a modification of Emlen's method. Studies in Avian Biology 6:483-487.

Ramsey, F. L., V. Wildman, and J. Engbring. 1987. Covariate adjustments to effective area in variable-area wildlife surveys. Biometrics 43:1-11.

Reynolds, R. T., J. M. Scott, and R. Nussbaum. 1980. A variable circularplot method for estimating bird numbers. Condor 82:309-313.

Scott, J. M., S. Mountainspring, F. L. Ramsey, and C. B. Kepler. 1986. Forest bird communities of the Hawaiian Islands: their dynamics, ecology and conservation. Studies in Avian Biology 9:1-431.

Scott, J. M., S. Mountainspring, C. van Riper III, C. B. Kepler, J. D. Jacobi, T. A. Burr, and J. G. Giffin. 1984. Annual variation in the distribution, abundance and habitat response of the palila (Loxioides bailleui). Auk 101:647-664.

Scowcroft, P. G., and J. G. Giffin. 1983. Feral herbivores suppress mamane (Sophora chrysophylla) and other browse species on Mauna Kea, Hawaii. Journal of Range Management 36:638-645.

Taylor, B. L., and T. Gerrodette. 1993. The uses of statistical power in conservation biology: the vaquita and northern spotted owl. Conservation Biology 7:489-500.

Thomas, L., J. L. Laake, S. Strindberg, F. F. C. Marques, S. T. Buckland, D. L. Borchers, D. R. Anderson, K. P. Burnham, S. L. Hedley, and J. H. Pollard. 2002. Distance 4.0. Release 2. Research Unit for Wildlife Population Assessment, University of St. Andrews, St. Andrews, United Kingdom. <www.ruwpa.st-and.ac.uk/distance/>. Accessed 2002 Jul 19.

United States Fish and Wildlife Service. 1986. Recovery plan for the palila. U.S. Fish and Wildlife Service, Portland, Oregon, USA.

van Riper, C., III 1980a. The phenology of dryland forests of Mauna Kea, Hawaii, and the impact of recent environmental perturbations. Biotropica 12:282-291.

van Riper, C., III 1980b. Observations on the breeding of the palila (Psittirostra bailleui) on Hawaii. Ibis 122:462-475.

van Riper, C., III, J. M. Scott, and D. M. Woodside. 1978. Distribution and abundance patterns of the palila on Mauna Kea, Hawaii. Auk 95: 518-527.

van Riper, C., III, S. G. van Riper, M. L. Goff, and M. Laird. 1986. The epizootiology and ecological significance of malaria in Hawaiian land birds. Ecological Monographs 56:327-344.

Warner, R. E. 1960. A forest dies on Mauna Kea. Pacific Discovery 13: $6-14$.

Warner, R. E. 1968. The role of introduced diseases in the extinction of the endemic Hawaiian avifauna. Condor 70:101-120.
Wolfe, E. W., and J. Morris. 1996. Geologic map of the island of Hawaii. U.S. Department of the Interior, U.S. Geological Survey Miscellaneous Investigations Series, Reston, Virginia, USA.



Luanne Johnson (photo) currently is a doctoral candidate at Antioch New England Graduate School. Her research focuses on the behavioral ecology and population dynamics of striped skunks (Mephitis mephitis) inhabiting coastal waterbird nesting areas on the island of Martha's Vineyard, Massachusetts, USA. Prior to working with palila in Hawai'i, she was a shorebird biologist on Martha's Vineyard and a backcountry guide in Alaska. She earned her bachelor's degree in zoology at Butler University, in Indianapolis. She maintains her passion for birds as well as her new study subjects, but also works on environmental education and citizen science projects. Richard J. (Rick) Camp is the project coordinator for the Hawaili Forest Bird Interagency Database Project of the United States Geological Survey's (USGS) Hawai'i Cooperative Studies Unit, University of Hawai'i at Hilo. He received his B.S. in wildlife management from the University of Minnesota and his M.S. in wildlife biology from Colorado State University. His current research interests include population estimation, distribution analysis, and survey design, primarily for Hawaiian birds. Kevin W. Brinck is a quantitative ecologist working for palila restoration. He obtained a B.S. in chemistry from Harvey Mudd College and an M.S. in quantitative ecology and resource management from the University of Washington. In between he spent 3 years as a disease control agent for Peace Corps in rural Mauritania. Paul C. Banko is a wildlife biologist with USGS Pacific Island Ecosystems Research Center. He received his B.S. in zoology and botany and Ph.D. in wildlife science from the University of Washington. His main research interest is the conservation biology of Hawaiian birds. He has been investigating the restoration ecology of palila since 1988 .

Associate Editor: Schweitzer. 